\title{
Avaliação da segurança no trabalho em obras de pequeno porte no setor Jardim Aeroporto, Porto Nacional/TO
}

A construção civil é um setor de grande representatividade para a economia brasileira, e tem apresentado um crescimento considerável ao longo dos anos. Entretanto, aliado ao seu crescimento, apresenta-se o aumento do número de acidentes do trabalho nesse ambiente. Isso acontece pela falta da aplicação das Normas Regulamentadoras no ambiente de trabalho da construção, onde há a ausência de segurança e saúde no trabalho. Verifica-se que esta ausência é bastante presente nas obras de pequeno porte, caracterizadas por haver até 20 funcionários, devido muitas vezes serem serviços artesanais e sem planejamento. Frente ao exposto, buscou-se realizar uma investigação quando a segurança no trabalho existente em obras de pequeno porte da construção civil, através da verificação de obras no setor Jardim Aeroporto, em Porto Nacional - TO, por se tratar de um setor novo, com constantes construções residenciais, além de ser um setor afastado, contribuindo para a dificuldade na fiscalização, e consequentemente no aumento de irregularidades que prejudiquem a segurança no trabalho. A pesquisa investigou três obras no setor mencionado, e identificou que há um descumprimento muito grande das normas regulamentadoras, oferecendo riscos à saúde e segurança dos trabalhadores e favorecendo a ocorrência de acidente no trabalho.

\section{Assessment of safety at work on small works in the Jardim Aeroporto sector, Porto Nacional/TO}

\begin{abstract}
Civil construction is a sector of great representation for the Brazilian economy, and has shown considerable growth over the years. However, coupled with it growth, there is an increase in the number of occupational accidents in this environment. This is due to the lack of application of Regulatory Standards in the construction work environment, where there is a lack of occupational safety and health. It is found that this absence is quite present in small works, characterized by having up to 20 employees, often because they are artisanal and unplanned services. In view of the above, an investigation was sought when the safety at work existing in small construction works, through the verification of works in the Garden Airport sector, in Porto Nacional - TO, because it is a new sector, with constant residential construction, in addition to being a remote sector, contributing to the difficulty in supervision, and consequently the increase of irregularities that jeopardize safety at work. The research investigated three works in the sector mentioned, and identified that there is a very large breach of regulatory standards, offering risks to the health and safety of workers and favoring the occurrence of accidents at work.
\end{abstract}

Keywords: Safety at work; Construction; Regulatory Standards; Works of small size.

Topic: Engenharia Civil

Reviewed anonymously in the process of blind peer
Received: $10 / 03 / 2019$

Approved: 29/07/2019
Laryssa Lopes Tavares

Instituto Tocantinense Presidente Antônio Carlos, Brasil

http://lattes.cnpq.br/7931611819542768

http://orcid.org/0000-0001-8435-5260

lopeslaryssa71@gmail.com

Eduardo Gouveia Santiago Lage

Instituto Tocantinense Presidente Antônio Carlos, Brasil

http://lattes.cnpq.br/4344949197847151

http://orcid.org/0000-0003-0011-2451

eduardolage@itpacporto.com.br

\section{Referencing this:}

TAVARES, L. L.; LAGE, E. G. S.. Avaliação da segurança no trabalho em obras de pequeno porte no setor Jardim Aeroporto, Porto Nacional/TO. Inventionis, v.1, n.2, p.30-38, 2019. DOI:

DOI: 10.6008/CBPC2674-6395.2019.002.0004
http://doi.org/10.6008/CBPC2674-6395.2019.002.0004 


\section{INTRODUÇÃO}

Segundo Moraes (2017), a indústria da construção civil possui um papel muito importante para a economia do Brasil, visto que envolve uma grande cadeia produtiva, gera riquezas e é capaz de gerar muitos empregos. Sua importância econômica é tamanha que impacta no Produto Interno Bruto - PIB do país, além de ter uma importância social em virtude da geração de emprego e renda (SOUSA JÚNIOR, 2012).

Apesar disso, nos últimos anos a construção civil tem crescido e por consequência também aumentou os riscos de acidentes neste ambiente de trabalho (PRATES et al., 2016). Silva et al. (2015) afirmam que para que uma obra tenha sucesso, a empresa deve cumprir e exigir os requisitos mínimos de segurança e saúde no trabalho, estabelecidos através das Normas Regulamentadoras, para prevenir os acidentes e/ou doenças em decorrência do trabalho.

No total, existem 37 Normas Regulamentadoras, sendo que 2 foram revogadas, havendo, portanto, 35 normas vigentes, sendo que há uma específica para a construção civil, a NR-18, que dispõe sobre as condições e meio ambiente de trabalho na indústria da construção, e mesmo havendo esta NR e outras afins, de modo a garantir a segurança e saúde na construção civil, há a notificação de altos índices de acidente no trabalho na construção civil, principalmente pela falta de cumprimento das normas e negligência na fiscalização (GOMES, 2011).

Segundo o INSS (2016), o acidente do trabalho é caracterizado como todo acidente que ocorre durante o exercício do trabalho, onde resulta em dano para o trabalhador, podendo ser divido entre acidente típico e trajeto, sendo os decorrentes de causas súbitas e inesperadas e durante o trajeto, e as doenças ocupacionais, que se caracterizam como os estados de doença provocados pelo processo de trabalho.

São verificados altos índices de acidentes no trabalho na construção civil, sendo que este é um dos setores com um dos maiores índices de acidente (SANTOS, 2018). Os índices de acidentes de trabalho no país são tão altos que chegam a 410 mil por ano, matam cerca de 3 mil pessoas e custam cerca de $R \$ 32$ bilhões ao país (SILVA, 2011). Somente no ano de 2017, houve a notificação de 549.405 acidente de trabalho em todo o país, e deste total, 30.025 se refere à acidentes no ambiente da construção civil, representando 5,46\% de todos os casos, além de haver uma taxa de mortalidade muito alta através de acidentes no setor, com 11,76 casos para cada grupo de 100 mil pessoas, sendo o dobro do valor de mortalidade no trabalho no geral do Brasil, com 5,21 mortes para cada 100 mil (ANAMT, 2019).

No entanto esses números podem ser ainda maiores, visto que nem todo acidente é notificado, principalmente quando o trabalho é irregular e informal, o que costuma acontecer bastante em obras de pequeno porte, onde há informalidade e precárias condições de trabalho (GOMES, 2011). Justificado pelo fato de haver uma fiscalização negligente, fazendo com que haja um menor cumprimento das normas se saúde e segurança no trabalho (SANTOS, 2018).

Dentro da construção civil, as obras de pequeno porte apresentam altos índices de negligência na segurança e saúde dos trabalhadores, pois a grande parte dessas obras são realizadas de forma artesanal e sem planejamento, sendo que estas se referem àquelas com até 20 funcionários (MORAES, 2017). Essas obras 
são caracterizadas como aquelas que possuem até quatro pavimentos, altura de pilares de até quatro metros, ausência de proteção, além de um canteiro de obras com menos de 20 empregados (MORAES, 2017; PINHEIRO, 2007).

$\mathrm{Na}$ grande maioria dos país, há uma grande dificuldade para as empresas de pequeno porte se adequarem aos padrões de segurança exigidos pelas legislações, e desse modo apresentam uma alta incidência de acidentes de trabalho, sendo que no Brasil os números são altos, visto que há um grande número de trabalhadores presentes nesses tipos de obra (SILVA, 2011).

Diante disso, o presente trabalho objetivou avaliar as condições de segurança no trabalho das obras de pequeno porte no setor Jardim Aeroporto, em Porto Nacional - TO, em virtude de o mesmo possuir um grande número de obras de pequeno porte, principalmente residenciais, além de ser um setor novo e afastado, podendo dificultar a fiscalização e favorecer a informalidade, condições precárias de trabalho e ausência da aplicabilidade das NRs.

\section{METODOLOGIA}

A pesquisa é caracterizada como do tipo descritiva, exploratória, bibliográfica e de campo, com abordagem qualitativa. Após a aprovação do projeto de pesquisa, buscou-se realizar a coleta de dados, não houve a necessidade de submissão e aprovação do Comitê de Ética em Pesquisa - CEP, visto que, apesar de a pesquisa buscar a verificação do trabalho desempenhado por trabalhadores da construção civil, não houve intervenção ou abordagem direta junto à seres humanos, conforme determina a Resolução no 466 de 2012.

A pesquisa foi realizada no município de Porto Nacional - TO, durante os meses de setembro, outubro e novembro de 2019. Segundo o Instituto Brasileiro de Geografia e Estatística - IBGE (2019), a cidade de Porto Nacional - TO possui uma população estimada de 53.010 habitantes para 2019. Foi realizada uma identificação de obras de pequeno porte no Setor Jardim Aeroporto, em Porto Nacional - TO, localizado em uma região com bairros periféricos no entorno, conforme a figura 1.

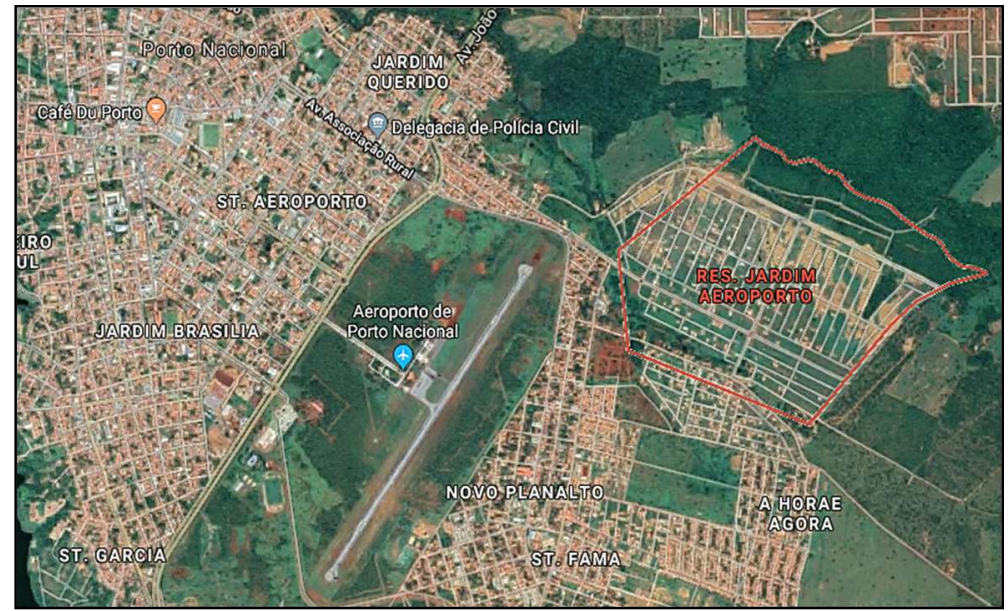

Figura 1: Localização do Setor Jardim Aeroporto em Porto Nacional - TO. Fonte: Google Maps (2019).

O setor Jardim Aeroporto é um loteamento relativamente novo na cidade de Porto Nacional - TO, localizado em uma área um pouco afastada, próximo a setor mais periféricos e à uma área verde. A 
localização do setor pode ser um fator dificultante na fiscalização constante das obras. Por ser um setor residencial, e um loteamento relativamente novo, há uma presença constante de obras residenciais, consideradas de pequeno porte, por possuírem menos de 20 funcionários.

Após a identificação de obras pelo setor, a partir de uma pesquisa a campo por todo o local se identificou 5 obras residenciais, além de algumas residenciais não finalizadas, porém já com moradores, onde aparentemente a continuidade da construção se dá aos poucos, inviabilizando a coleta de dados nas mesmas. Nesse sentido, após essa identificação, foi realizada uma abordagem junto aos responsáveis pelas cinco obras, obtendo anuência de três para a verificação da segurança e saúde no ambiente de trabalho.

A verificação se deu a partir da observação de fatores dispostos nas Normas Regulamentadoras, referentes à segurança no trabalho, sendo: agilidade dos trabalhadores no desempenho de suas funções, uso de EPIs e uniformes (botina, luvas, óculos, capacete, calça, bonés, e afins), uso de EPI para trabalhos em altura, transporte de materiais, segurança em andaimes, presença de um responsável na obra para verificação do uso de EPI e cumprimento de exigências para a segurança no trabalho, verificação de equipamentos com condições precárias, presença de Engenheiro Civil responsável pela obra, placa de identificação da obra.

De modo a preservar a identidade dos trabalhadores, não foi tirado nenhuma foto que identificassem os mesmos. A partir da coleta, realizou-se a análise dos dados, a partir da identificação do cumprimento das Normas Regulamentadoras nas obras, utilizando estudos afins para a comparação. As principais Normas Regulamentadoras utilizadas foram: Norma Regulamentadora no 6 (NR 6), Norma Regulamentadora no 11 (NR 11), Norma Regulamentadora no 17 (NR 17) e Norma Regulamentadora no 18 (NR 18).

Realizou-se uma análise a partir de uma linguagem discursiva, descrevendo as falhas e pontos negativos das obras, incluindo o descumprimento não somente das normas regulamentadoras, como também o descumprimento de normas e exigências mínimas para a construção civil, como por exemplo, a ausência de placa de identificação das obras, conforme determina as políticas e normas do município e as exigências do Conselho Regional de Engenharia e Agronomia - CREA do Tocantins.

\section{RESULTADOS E DISCUSSÃO}

Ao verificar as obras no setor Jardim Aeroporto em Porto Nacional - TO, obteve-se a autorização para observar a saúde e segurança no trabalho em três obras residenciais. As obras foram identificadas como obra 1, obra 2 e obra 3. Na obra 1 haviam cinco funcionários, sendo: um mestre de obras, três pedreiros e um ajudante de pedreiro. Na obra 2 haviam três funcionários, sendo: um pintor, um pedreiro e um ajudante. Na obra 3 haviam três funcionários, sendo: um pedreiro, um ajudante e um mestre de obras.

Ao avaliar a agilidade dos trabalhadores no desempenho de suas funções, identificou-se que somente o ajudante de pedreiro da obra 1 apresentava dificuldade, visto que necessitava atender a três pedreiros. Verificou-se que em nenhuma obra havia Engenheiro Civil, tampouco algum outro profissional habilitado para o comando da obra. Nas obras 1 e 3 o responsável por cada uma se tratava de mestres de obras. Segundo Gomes (2011), as obras de pequeno porte costumam ser dirigidas apenas por 
mestres/encarregados de obras, que não possuem formação necessária para lidar com a saúde e segurança no trabalho, o que contribui para o aumento da informalidade e da exposição dos trabalhadores aos riscos de acidentes no trabalho.

Já na obra 2, cabe ressaltar que o ajudante se trata do dono da obra, não havendo sequer um mestre de obras para o comando da equipe, onde o dono da obra assume esse papel, havendo até mesmo um maior nível de informalidade que nas outras obras verificadas, visto que em virtude de o mesmo possuir algum conhecimento com construção civil, há uma maior chance de ele contratar outros trabalhadores apenas na diária ou a chamada empreita.

Nesse sentido, identifica-se que essa questão de informalidade verificada influencia no uso de Equipamento de Proteção Individual - EPI por parte dos funcionários, conforme determinado pela Norma Regulamentadora no 6 (NR 6). Sendo que nas obras 1 e 3, onde há mestre de obras, os trabalhadores utilizam alguns EPIS e uniformes, e na obra 2 os trabalhadores faziam o uso somente de botina, e um trabalhador não utilizava nenhum equipamento ou uniforme, conforme demonstrado no quadro 1.

Quadro 1: Uso de EPI e uniforme pelos trabalhadores das obras analisadas.

\begin{tabular}{|c|l|l|l|}
\hline & Obra 1 os & Obra 2 & Obra 3 \\
\hline EPI & $\begin{array}{l}\text { Todos } \\
\text { trabalhadores faziam } \\
\text { o uso de botinas, luvas } \\
\text { e bonés }\end{array}$ & $\begin{array}{l}\text { Pedreiro e ajudante faziam o } \\
\text { uso de botina e o pintor fazia } \\
\text { o serviço com chinelo }\end{array}$ & $\begin{array}{l}\text { O pedreiro fazia o uso de botas, o ajudante fazia o uso de luvas } \\
\text { e óculos escuros, e o mestre e obras não utilizava nenhum EPI }\end{array}$ \\
\hline $\begin{array}{l}\text { Uni } \\
\text { for } \\
\text { me }\end{array}$ & $\begin{array}{l}\text { Todos os } \\
\text { trabalhadores faziam } \\
\text { o uso de calça e edreiro e ajudante } \\
\text { camisa }\end{array}$ & $\begin{array}{l}\text { Pedilizavam calça e camisa, e o } \\
\text { utintor faz o serviço com } \\
\text { bermuda }\end{array}$ & $\begin{array}{l}\text { Nenhum trabalhador utilizava uniforme. O pedreiro estava de } \\
\text { camiseta e calça, o ajudante estava de camisa, bermuda e } \\
\text { chinelo, e o mestre de obras com calça, camisa e chinelo }\end{array}$ \\
\hline
\end{tabular}

Ao considerar que a obra 1 encontrava-se na fase de levantamento de paredes, concretagem de vigas e pilares e detalhes para a cobertura, identifica-se que os trabalhadores faziam o uso de grande parte dos EPIs necessários, entretanto há uma preocupação quanto ao uso de capacetes, além da ausência do uso de óculos. Apesar disso, verifica-se que a obra 1 é a que possui as melhores condições de uso de EPI, sendo a obra com o maior número de trabalhadores, e gerenciada por um mestre de obras.

A obra 2 se encontrava na fase de pintura interna e construção do muro, nesse sentido, verifica-se que para a construção do muro, o pedreiro e o ajudante se encontravam com o uso inadequado de EPI, com ausência de luvas, capacetes e óculos. Já o pintor encontrava-se com uma ausência no uso de EPI necessários à sua função, como botinas, luvas, máscaras, óculos, além de trajes impróprios, sendo esta uma situação comum verificada à essa classe de trabalhadores.

Já a obra 3 encontrava-se na fase de levantamento de paredes e concretagem de viga e pilares. Verifica-se um ponto mais negativo, visto que o mestre de obras, responsável pelo gerenciamento da equipe, encontrava-se com trajes inadequados, sem o uso de botina ou outro EPI, e isso influencia na utilização pelos outros trabalhadores, que não possuem um líder para se espelhar na questão do uso de EPI.

Identificou-se que nenhuma obra possuía engenheiro responsável, tampouco placa de identificação da obra, desse modo, esses fatores indicam que se tratam de obras informais e irregulares, o que contribui para não haver uma distribuição de EPIs. Cisz (2015) argumenta que, apesar da importância do uso de EPI, 
que pode salvar a vida dos trabalhadores, é muito comum a não disponibilização dos mesmos pelos empregadores, mesmo que esta seja uma obrigação, além de haver uma não utilização dos EPIs pelos trabalhadores, principalmente em obras de pequeno porte, devendo haver uma fiscalização eficiente, para a garantia do cumprimento dos direitos e deveres, evitando falhas no sistema construtivo.

De acordo com Sousa Junior et al. (2012), os principais EPIs utilizados na construção civil são: capacete de segurança para proteção a cabeça contra impactos de objeto sobre o crânio; equipamentos para proteção dos olhos e faces, como óculos, protetor facial, máscaras; protetor auditivo; protetor respiratório; vestimentas para proteger o tronco; equipamentos para proteção dos membros superiores, como o uso de luvas e vestimentas com mangas; equipamentos para proteção dos membros inferiores, como o uso de botinas e calças; equipamentos para proteção contra quedas.

Identificou-se que uma grande parte dos trabalhadores fazem o uso de botina e luvas, entretanto verifica-se que em nenhuma obra havia algum trabalhador fazendo o uso de capacete, e ao considerar que as obras estavam na fase de levantamento de paredes e muros, há o perigo de acidente a partir da queda de algum material na cabeça desprotegida, podendo, desse modo, ser fatal.

Além disso, há trabalhadores sem fazerem o uso de nenhum EPI, o que é ainda mais preocupante, pois a exposição a riscos de acidente no trabalho é ainda maior. Frente ao exposto, identifica-se que, no geral, as três obras verificadas não cumprem a exigência do uso de EPI, conforme determinado pela Norma Regulamentadora no 6 (NR 6), e apesar de alguns trabalhadores fazerem o uso de alguns, não é suficiente para a proteção contra acidentes no trabalho.

No que se refere ao transporte de materiais, verificou-se que somente na obra 3 os trabalhadores realizam o transporte de materiais através de carrinhos de mão, transportando um peso visivelmente suportável. Já na obra 1, os trabalhadores realizavam o transporte tanto por carrinhos, quanto manual, sendo que foi verificado, durante a pesquisa em campo, a realização de transportes de sacos de cimento de forma manual, levando-os nos braços e costas, visível e aparentemente realizando um esforço muito grande. $\mathrm{Na}$ obra 2, apesar de o transporte ser manual, ele estava sendo dividido por dois trabalhadores, onde os mesmos estavam realizando esforços visivelmente suportáveis.

A Norma Regulamentadora no 11 (NR 11) - Transporte, Movimentação, Armazenagem e Manuseio de Materiais, de um modo geral, trata da segurança necessária para a operação de elevadores, guindastes, transportadores industriais e máquinas transportadoras, além de carros manuais para o transporte de materiais, e o transporte manual. Nesse sentido, segundo a NR 11, os carros manuais utilizados para transporte de materiais devem possuir protetores das mãos, e nos transportes com equipamentos de força motriz própria, o operador deverá receber treinamento específico pela empresa, além disso, o transporte manual de um saco deve obedecer a um limite de sessenta metros, e não podem ser realizados por meio de pranchas e vãos acima de um metro (BRASIL, 2016).

Identifica-se, portanto, que a NR 11 não determina a proibição do transporte manual somente por um trabalhador, só específica o limite de metros a serem percorridos. Na obra 1, o transporte de sacos de cimento se realizou por um trecho menor de 60 metros, entretanto, ainda assim, houve um grande esforço 
para a realização do transporte, o que pode prejudicar a saúde do trabalhador.

Desse modo, a Norma Regulamentadora no 18 (NR 18), que trata das condições e meio ambiente de trabalho na indústria da construção, diz que "o levantamento manual ou semimecanizado de cargas deve ser executado de forma que o esforço físico realizado pelo trabalhador seja compatível com a sua capacidade de força, conforme a NR-17 (Ergonomia)" (BRASIL, 2018).

A Norma Regulamentadora no 17 (NR 17) trata sobre a Ergonomia no ambiente de trabalho, determina que, devem haver condições de trabalho que proporcione o máximo de conforto, segurança e desempenho eficiente possível aos trabalhadores, relacionado as características psicofisiológicas. Para isso, determina a adaptação do trabalhador ao seu serviço, como em situações de levantamento, transporte e descarga de materiais manualmente, trabalhos sentados ou em pé, além da definição do tempo de serviço, iluminação, níveis de ruído, temperatura, e todas as características para manter o conforto, saúde e segurança do trabalhador. Dentre as exigências de ergonomia, determina que o trabalhador não pode realizar um transporte manual de cargas com um peso que comprometa sua saúde ou segurança, e quando este transporte for feito por meio de aparelhos mecânicos, como carros de mão, também não deve ser feito com um esforço físico que comprometa sua saúde ou segurança (BRASIL, 2018).

Logo, identifica-se que o transporte manual realizado na obra 1 descumpre o disposto nas NR $18 \mathrm{e}$ NR 17. Ao verificar a questão do trabalho em alturas, identificou-se que este se dá a partir de andaimes nas obras 1 e 3, por serem obras ainda em fase de levantamento de paredes e concretagem. Em nenhuma das obras os andaimes se encontravam regulares, conforme as figuras 2 e 3.

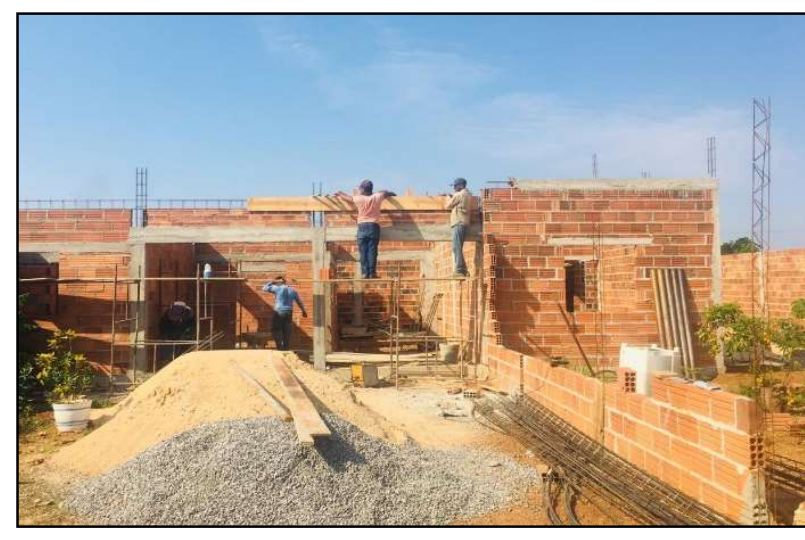

Figura 3: Trabalhadoras da obra 1 realizando trabalhos em andaimes de modo irregular.

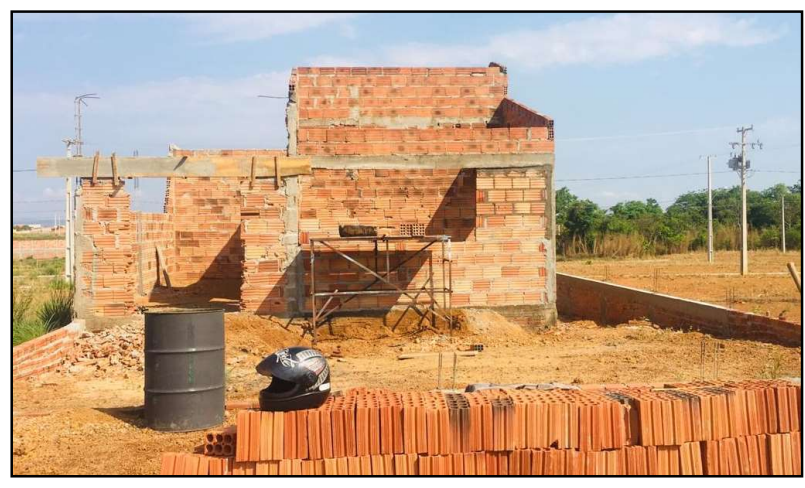

Figura 2: Andaime irregular na obra 3.

Identifica-se que os trabalhadores na obra 1, vistos na figura 2, trabalham sem nenhuma segurança, sem o uso de cinto de segurança. Além disso, os andaimes não dispõem de piso de trabalho, tampouco de guarda-corpo para proporcionar segurança aos trabalhadores. Já os andaimes da obra 3, vistos na figura 3 , não dispõem de guarda-corpo, e o piso de trabalho é apenas de madeira, disposto de forma solta. A NR 18 determina que os andaimes para obras da construção civil devem possuir estrutura de sustentação e fixação, com piso antiderrapante fixado de modo seguro e resistente, disporem de guarda-corpo e rodapé, além de ser obrigatório o uso de cinto de segurança tipo paraquedista e com duplo talabarte para os trabalhadores (BRASIL, 2018). 


\section{CONCLUSÕES}

A partir da pesquisa realizada, verificou-se que as obras de pequeno porte empregam pessoas com diversos graus de instrução, desempenhando uma importância econômica e social. Apesar disso, verifica-se uma negligência quanto à contratação de mão de obra qualificada referente à contribuição à saúde e segurança no trabalho de obras de pequeno porte no Setor Jardim Aeroporto, em Porto Nacional - TO.

A ausência de engenheiro civil ou algum profissional afim, se apresenta como um fator preocupante, tanto no que se refere à saúde e segurança dos trabalhadores, quanto no bom andamento da obra. Apesar de as obras verificadas possuírem mestres de obra ou profissionais com conhecimento na construção civil, como pedreiros, o conhecimento dos mesmos não é suficiente para a garantia de segurança. Nesse sentido, esse fator descumpre o determinado pelas normas de postura e obras do município de Porto Nacional, onde todo município obriga a necessidade de um Engenheiro Civil ou Arquiteto na realização de uma obra, além de descumprir o mesmo determinado pelo CREA.

Identifica-se que as obras observadas seguem os dados descritos por outros estudos, por serem informais e até mesmo irregulares, verificadas a partir da ausência de placa de identificação e engenheiro civil. Por serem obras residenciais, com ausência dos fatores citados, acredita-se que são construções feitas a partir de contratações por diária, sem uma regularização, bem como sem o cumprimento e exigência de normas regulamentadoras para a garantia de segurança no trabalho.

Por esse motivo, foram identificadas a ausência no uso de EPIs fundamentais à realização das funções dos trabalhadores, descumprindo a Norma Regulamentadora no 6 (NR 6); ausência de exigências relacionadas ao transporte de materiais, descumprindo a Norma Regulamentadora no 11 (NR 11), Norma Regulamentadora no 17 (NR 17) e Norma Regulamentadora no 18 (NR 18); e ausência das exigências relacionadas aos andaimes das obras, descumprindo a Norma Regulamentadora no 18 (NR 18).

A ausência do cumprimento das exigências e determinações das Normas Regulamentadoras é um fator preocupante, diretamente relacionado à exposição de riscos de acidente no trabalho. Ao considerar a informalidade dessas obras, pode-se argumentar que a ocorrência de acidente no trabalho nas mesmas é um fator ainda mais preocupante que nas obras regulares, visto que não há nenhuma garantia ao trabalhador.

Frente ao exposto, verifica-se a necessidade de haver uma maior fiscalização junto às obras de pequeno porte, visto que, observa-se que, por haver descumprimentos tão significativos, a fiscalização é negligente. Apesar de o setor ser um pouco afastado e próximo a setores periféricos, são características que não devem influenciar na fiscalização, tanto por parte do município, quanto por parte do CREA.

Ressalta-se que, apesar de Porto Nacional ser uma cidade relativamente grande, dentre as principais do estado, a agência do CREA foi fechada na cidade, na metade do ano de 2019. Desse modo, há uma maior dificuldade na fiscalização, visto que a agência mais próxima fica em Palmas - TO, que atende não somente Porto Nacional, como também outras cidades.

A mudança no cenário fiscalização pode impactar positivamente para a mudança das características das obras de pequeno porte, sendo indiscutível que as mesmas apresentam um alto grau de informalidade. 
Além da fiscalização, deve haver uma maior consciência por parte dos empregadores e trabalhadores, devendo os mesmos prezarem pela saúde e segurança.

\section{REFERÊNCIAS}

ANAMT. Associação Nacional de Medicina do Trabalho. Construção civil está entre os setores com maior risco de acidentes de trabalho. São Paulo: ANAMT, 2019.

BRASIL. Ministério do Trabalho e Emprego. NR 6: Equipamento de Proteção Individual - EPI. Brasília, 1978, alterada em 2018.

BRASIL. Ministério do Trabalho e Emprego. NR 11: Transporte, Movimentação, Armazenagem e Manuseio de materiais. Sendo de 1978, alterada 2016. Brasília: MTE, 2016.

BRASIL. Ministério do Trabalho e Emprego. NR 17: Ergonomia. Sendo de 1978, alterada 2018. Brasília: MTE, 2018.

BRASIL. Ministério do Trabalho e Emprego. NR 18: Condições e meio ambiente de trabalho na indústria da construção. Sendo de 1978, alterada 2015. Brasília: MTE, 2015.

CISZ, C. R.. Conscientização do uso de EPI's, quanto à segurança pessoal e coletiva. Curitiba: Universidade Tecnológica Federal do Paraná, 2015.

GOMES, H. P.. Construção civil e saúde do trabalhador: um olhar sobre as pequenas Obras. Rio de Janeiro: Fundação Oswaldo Cruz, 2011.

IBGE. Instituto Brasileiro de Geografia d Estatística. Porto Nacional. Rio de Janeiro: IBGE, 2019.

INSS. Instituto Nacional do Seguro Social. Manual de acidente de trabalho. Brasília: INSS, 2016.
MORAES, L. D.. Análise da aplicabilidade das normas regulamentadoras em obras de pequeno porte da construção civil. ljuí: Universidade Regional do Noroeste do Estado do Rio Grande do Sul, 2017.

PINHEIRO, L. M.. Fundamentos do concreto e projeto de edifícios. São Carlos: Universidade de São Paulo, 2007.

PRATES, A. E.; VARGAS, M. L.; QUEIROZ, D. P. P.; FINELLI, L. A. C.. Uso de equipamento de proteção individual pelos trabalhadores da construção civil. Revista Bionorte, v.5, n.2, p.77-86, 2016.

SANTOS, P. V. S.. Aplicação de Normas Regulamentadoras de Segurança do Trabalho em Obras de Pequeno Porte. Uberlândia: Universidade Federal de Uberlândia, 2018.

SILVA, A. L. C.. A segurança do trabalho como uma ferramenta para a melhoria da qualidade. Santa Maria: Universidade Federal de Santa Maria, 2011.

SILVA, A. M.; DIAS, I. F.; EVANGELISTA, W. L.. Análise de adequação de uma obra de pequeno porte, situada no oeste de Minas Gerais, com a Norma Regulamentadora 35 para trabalhos em altura: estudo de caso. In: ENEGEP ENCONTRO NACIONAL DE ENGENHARIA DE PRODUÇÃO, 35. Anais. Fortaleza, 2015.

SOUSA JUNIOR, A. M.; VALE, I. L. O.; ALVES, M. A. H.; SILVA, M. M.; FONSECA, S. K. R.. Viabilidade da utilização de EPIs e EPCs na construção de edificações de uso unifamiliar: estudo de multicaso na região da zona sul do município de Mossoró/RN. In: ENEGEP - ENCONTRO NACIONAL DE ENGENHARIA DE PRODUÇÃO, 32. Anais. Bento Gonçalves, 2012.

A CBPC - Companhia Brasileira de Produção Científica (CNPJ: 11.221.422/0001-03) detém os direitos materiais desta publicação. Os direitos referem-se à publicação do trabalho em qualquer parte do mundo, incluindo os direitos às renovações, expansões e disseminações da contribuição, bem como outros direitos subsidiários. Todos os trabalhos publicados eletronicamente poderão posteriormente ser publicados em coletâneas impressas sob coordenação da Cognitionis Publishing, da Companhia Brasileira de Produção Científica e seus parceiros autorizados. Os (as) autores (as) preservam os direitos autorais, mas não têm permissão para a publicação da contribuição em outro meio, impresso ou digital, em português ou em tradução. 